\title{
Investigating production parameters and impacts of potential emissions from soybean biodiesel stored under different conditions
}

\author{
Ayodeji Ayodele Ayoola ${ }^{{ }^{\dagger}}$, David Olalekan Adeniyi ${ }^{2}$, Samuel Eshorame Sanni ${ }^{1}$, \\ Kamsiyonna Ikenna Osakwe ${ }^{1}$, Jennifer Doom Jato ${ }^{1}$ \\ ${ }^{1}$ Chemical Engineering Department, Covenant University, 112242 Ota, Nigeria \\ ${ }^{2}$ Chemical Engineering Department, Federal University of Technology, 920281 Minna, Nigeria
}

\begin{abstract}
Biodiesel production parameters and the impact analysis of the potential emissions from both soybean biodiesel and washing water stored in three different environmental conditions were investigated. The effects of the reaction temperature, methanol/oil mole ratio and catalyst concentration on biodiesel yield were considered. And the results showed optimum biodiesel yield of $99 \%$ obtained at $54{ }^{\circ} \mathrm{C}$, $7 \mathrm{methanol} / \mathrm{oil}$ mole ratio and $0.4 \mathrm{wt} / \mathrm{wt} \%$ catalyst concentration. The potential emissions from both the biodiesel produced and washing water stored (for six weeks) in refrigerator $\left(\leq 10^{\circ} \mathrm{C}\right)$, vacuum $(50 \mathrm{kPa})$ and direct exposure to atmosphere were identified and quantified. Impact analysis of the emissions involved their categorization into: terrestrial acidification, freshwater eutrophication, human toxicity, terrestrial ecotoxicity, climate change and freshwater ecotoxicity. Freshwater ecotoxicity category had the most pronounced negative impact of the potential emissions with

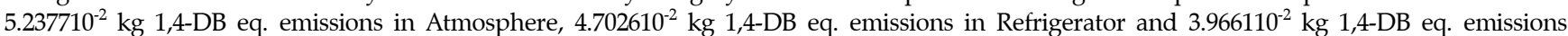
in Vacuum. Climate change had the least effect of the emissions with $6.21410^{-6} \mathrm{~kg} \mathrm{CO}_{2}$ eq. in Atmosphere, $3.9310^{-6} \mathrm{~kg} \mathrm{CO} 2$ eq. in Refrigerator and $1.6710^{-6} \mathrm{~kg} \mathrm{CO}_{2}$ eq. in Vacuum. The study showed that the order of preference of the storage environments of biodiesel is vacuum environment, refrigerated condition and exposure to atmosphere.
\end{abstract}

Keywords: Acidification, Biodiesel yield, Ecotoxicity, Emissions, Environment, Transesterification

\section{Introduction}

Energy production from biomass (such as woods, seed oils, agricultural residues) has a wide range of great advantages over fossil fuel [1-4]. The benefits include energy sustainability, reduction in pollution and global warming effects, increased energy diversification and economic security [5-7]. Biodiesel is a renewable biomass energy source. It can be produced through transesterification process which involves reversible chemical reaction between the triglycerides of plant oils or animal fats and short chain alcohol, in the presence of a catalyst (homogeneous or heterogeneous in nature) [8-10].

The production of high yield and quality biodiesel depends majorly (among other factors) on the choice of scientifically assessed production parameters [3, 11]. The production parameters include alcohol/oil mole ratio, catalyst type and concentration, reaction temperature, reaction time and speed of agitation.
Stoichiometric equation of biodiesel production shows that 3 moles of alcohol/oil triglyceride is required. However, it has been established by various researchers that alcohol/oil triglyceride mole ratio must exceed 3 for complete reaction to occur [12-16].

Research has shown that homogenous catalysis (involving $\mathrm{NaOH}$ or $\mathrm{KOH}$ ) produces higher conversion or yield of biodiesel, lower reaction temperature and lower reaction time when compared to heterogenous catalysis [12-13]. Also, base catalyzed process eliminates engine corrosion problem associated with the acid catalyzed process [14-15]. For base catalyzed methanolysis process, the optimal condition ranges are $55-62^{\circ} \mathrm{C}$ reaction temperature, 60-90 min reaction time and 250-350 rpm [1-3, 14-15].

One problem associated with the long time storage of biodiesel is change in its properties and this may result into a decrease in its quality. As recommended by ASTM, high quality biodiesel has zero or negligible free fatty acid content (0.05\% maximum), zero or negligible moisture content $(0.05 \%$ maximum), high cetane
This is an Open Access article distributed under the terms of the Creative Commons Attribution Non-Commercial License (http://creativecommons.org/licenses/by-nc/3.0/) which permits unrestricted non-commercial use, distribution, and reproduction in any medium, provided the original work is properly cited.

Copyright (C) 2018 Korean Society of Environmental Engineers
Received April 3, 2017 Accepted August 23, 2017

${ }^{\dagger}$ Corresponding author

Email: ayodeji.ayoola@covenantuniversity.edu.ng Tel: +234-8035624739

ORCID: 0000-0003-1653-2872 
number (47.0 minimum) and low level of impurities $(0.0015 \%$ mass maximum) [10, 13]. The storage environment in which biodiesel is subjected to can contribute to the nature and extent of impurities found in the biodiesel. This is because biodiesel (an oxygenated and unsaturated compound) can undergo certain reactions with certain compounds in such environment, depending on the environmental condition [17-20].

Thermolytic reaction, oxidative reaction, hydrolytic reaction and photolytic reaction are the common reactions that biodiesel experienced when stored in different environments [19, 21]. That is, biodiesel undergoes these chemical reactions when exposed to heat, air and light for a period of time. And the reactions produce unwanted products as impurities [22-24].

These contaminants (impurities) when released during biodiesel fuel utilization affect the engine, human health and environment $[2,25]$. For instance, the release of $\mathrm{CO}_{\mathrm{x}}, \mathrm{NO}_{\mathrm{x}}$, and $\mathrm{SO}_{2}$, contribute to acidification and global warming; the release of phosphates causes eutrophication; and the release of tetra-chlorides and benzene can result in terrestrial and freshwater toxicity [7, 26-28].

The environmental impacts of the potential emissions from the biodiesel utilization can be accurately quantified, characterized and analysed using life cycle assessment (LCA). LCA of biodiesel involves an investigation and evaluation of the effects of the emission from biodiesel. Most studies on emission impacts of bioenergy focus on the global warming potential (GWP) [29]. In recent years, emission impacts have become a key focus in environmental policy making and clean energy. Examples of these are the 'Integrated product policy (IPP) concept' [30] and 'The 2030 Agenda for Sustainable Development' [31]. LCA of the potential emissions from biodiesel involves goal (scope) definition, inventory analysis, characterization of the potential emissions and the impact analysis of such emissions on man and his environment [32-33].

In this research work, biodiesel production factors and the impacts of potential emissions from soybean biodiesel stored in three different environmental conditions will be investigated. That is, the work is to consider the effects of storing biodiesel in three different environments by identifying, analysing and comparing the various emissions obtained from the biodiesel stored in theses environments. The storage environments for consideration in this work are direct exposure to the atmosphere, refrigeration and vacuum.

\section{Materials and Methods}

\subsection{Materials, Reagents and Equipment}

Soybean oil, the raw material, was purchased from a local supermarket in Ota, Nigeria.

The chemical reagents used include n-hexane (98\%, SigmaAldrich, UK), Ethanol (96\%, J.T Baker, USA), methanol (99.8\%, Romil Ltd., UK), Sodium Hydroxide (98\%, Qualikems, India), Potassium Hydroxide pellets (95\%, Riedel-Dietaen, Germany), Hydrochloric acid (98\%, Sigma-Aldrich, UK), Calcium carbonate (98\%, Romil Ltd., UK), Tetraoxosulphate(VI) acid (98\%, J.T Baker,
USA), and benzene (97.7\%, Sigma-Aldrich, UK)

The equipment used in the course of this research work include Atomic Absorption Spectroscopy (AAnalyst 200 Perkin Elmer precisely, USA), C 99 Multiparameter Bench Photometer HANNA, Pensky-Martens Automatic Closed Tester, (Normalab NPM 440) with refrigerating cooling system, Viscometer Bath VB-1423 (P SELECTA) with U tube Ostwald Viscometer and pipette filler (Spain). Julabo F12 (France), Cimarec Digital Magnetic Stirring Hot Plate (7.25" 7.25", USA), Anton Paar DMA 38 Density Meter (USA), Pour Point Tester (Lawler Manufacturing Corporation, USA).

\subsection{Design of Experiment}

Experimental design for biodiesel production was carried out using Box-Behnken $B B(3)$ method (MINITAB 17 software) and the three production parameters (factors) considered were reaction temperature, methanol/oil mole ratio and catalyst concentration (Table 1).

Table 1. Experimental Design and Experimental Runs with the Biodiesel Yield Obtained

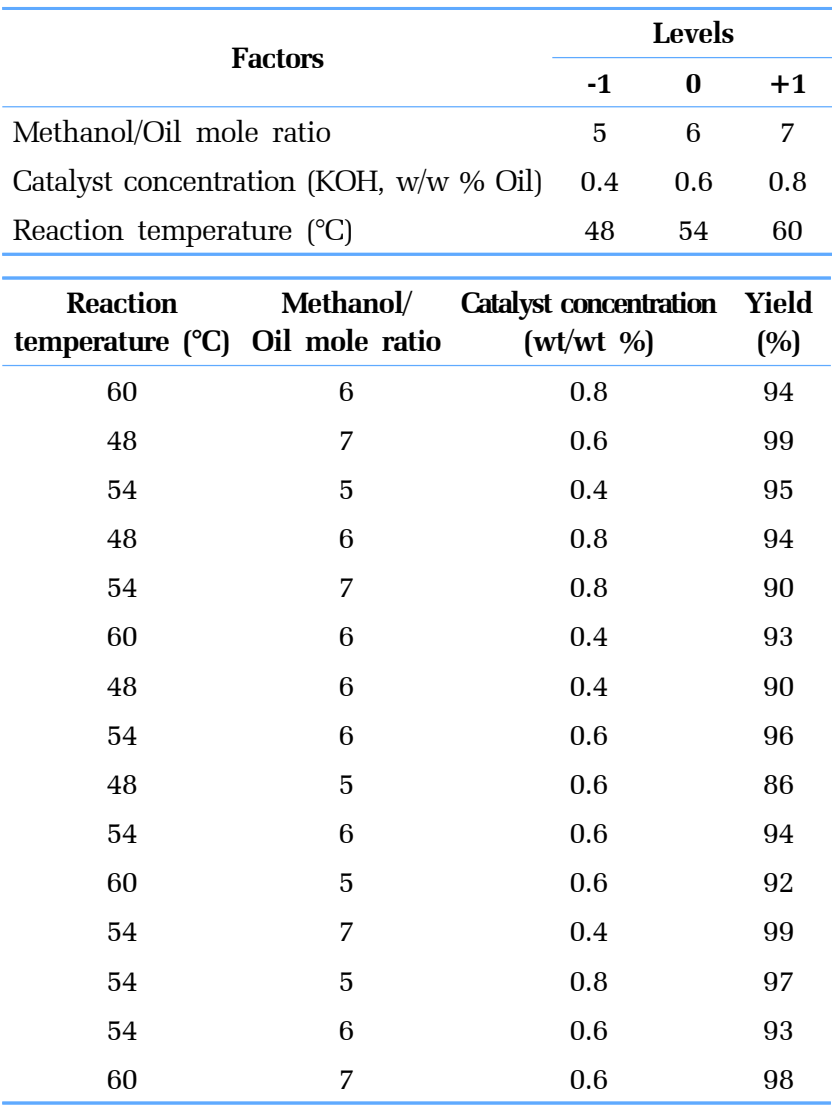

\subsection{Biodiesel Production}

Biodiesel was produced through transesterification process that involved reaction between the triglycerides of oil and methanol in the presence of potassium hydroxide (catalyst), glycerol was obtained as byproduct. The oil sample was first pretreated by removing impurities and water present. 
$100 \mathrm{~g}$ of the pretreated oil was heated and maintained at $60^{\circ} \mathrm{C}$ in an air-tight tri-neck flat bottom flask. $\mathrm{KOH}$ pellets were weighed and dissolved in methanol solution in a conical flask, the mixture was transferred into the tri-neck flat bottom flask containing the hot oil. The transesterification reaction was maintained at 300 rpm (using hotplate magnetic stirrer) and at the required temperature for a reaction time of $90 \mathrm{~min}$. A condenser was incorporated into the experimental setup to prevent the escape of any reagent in vapour form, biodiesel produced was separated from glycerol using separating funnel by leaving the content for $2 \mathrm{~h}$ when two distinct layers of upper biodiesel and lower layer of glycerol were obtained.

The impure biodiesel obtained was then washed with warm water continuously to remove impurities present and the sample was then dried in an oven at $110^{\circ} \mathrm{C}$ for $15 \mathrm{~min}$ to remove water present in the biodiesel. Table 1 shows the experimental design and biodiesel yield obtained from the experimental runs, while Table 2 shows the properties of the biodiesel produced.

Table 2. Physical Properties of Biodiesel Produced

\begin{tabular}{cccc}
\hline $\begin{array}{c}\text { Viscosity } \\
\text { Biodiesel }\end{array}$ & \multicolumn{3}{c}{ Flash point Pour point } \\
$\left(\mathrm{mm}^{2} / \mathrm{s} @ 40^{\circ} \mathrm{C}\right)$ & $\left({ }^{\circ} \mathrm{C}\right)$ & $\begin{array}{c}\text { Density } \\
\left({ }^{\circ} \mathrm{C}\right)\end{array}$ & $\left(\mathrm{kg} / \mathrm{m}^{3} @ 28^{\circ} \mathrm{C}\right)$ \\
\hline 4.4 & 175 & -7 & 860 \\
\hline
\end{tabular}

\subsection{Biodiesel Storage Conditions}

Biodiesel obtained was divided into three parts and stored under three different environmental conditions for six weeks. This was done so as to determine and compare the effects of storage con- ditions on both the quality of the biodiesel and the environment The three storage conditions considered were: direct exposure to the atmosphere, storage in refrigerator (at $\leq 10^{\circ} \mathrm{C}$ ) and vacuum condition (at pressure of $50 \mathrm{kPa}$ ).

\subsection{Elemental Analysis}

Elemental analysis of the potential emissions from the biodiesel produced and washing water was carried out in the Instrumentation Laboratory, Covenant University, using Atomic Absorption Spectroscopy (AAS, AAnalyst 200 Perkin Elmer precisely, USA) spectrophotometer and C99 multi-parameter bench photometer (HANNA, USA). Biodiesel samples were first digested using wet digestion process. Table 3 shows the elements identified and their concentrations.

\subsubsection{Digestion of biodiesel and washing water samples}

$5 \mathrm{~g}$ of each sample and $100 \mathrm{~mL}$ of a solution containing concentrated HCL and $\mathrm{HNO}_{3}$ (in the volume ratio of 3:1) were heated in a film cupboard until the yellowish pungent fumes released became colorless, distilled water was then added to have $100 \mathrm{~mL}$ of the sample.

\subsubsection{AAS analysis on biodiesel samples}

Each of the digested samples was aspirated into the nebulizer compact where the sample mixed with air and acetone to form a mixture. Flame burned and atomized the sample from ground state to the excited state. At excited state, absorption occurred and monochromator selected the wavelength in agreement with the atom. And detector detected the atom and then transferred the concentration reading to the reader.

Table 3. Elements Identified in Biodiesel and Washing Water after Storage

\begin{tabular}{|c|c|c|c|c|c|c|}
\hline & \multicolumn{3}{|c|}{ Biodiesel } & \multicolumn{3}{|c|}{ Washing water } \\
\hline & $\begin{array}{c}\text { Atmosphere } \\
(\mu \mathrm{g} / \mathrm{L})\end{array}$ & $\begin{array}{l}\text { Refrigerator } \\
(\mu \mathrm{g} / \mathrm{L})\end{array}$ & $\begin{array}{c}\text { Vacuum } \\
(\mu \mathrm{g} / \mathrm{L})\end{array}$ & $\begin{array}{c}\text { Atmosphere } \\
(\mu \mathrm{g} / \mathrm{L})\end{array}$ & $\begin{array}{c}\text { Refrigerator } \\
(\mu \mathrm{g} / \mathrm{L})\end{array}$ & $\begin{array}{r}\text { Vacuum } \\
(\mu \mathrm{g} / \mathrm{L})\end{array}$ \\
\hline Aluminium & 0.033 & 0.028 & 0.030 & 0.055 & 0.048 & 0.039 \\
\hline Arsenic & 0.091 & 0.010 & 0.088 & nd & nd & nd \\
\hline Beryllium & 0.067 & 0.058 & 0.053 & nd & nd & nd \\
\hline Copper & 0.054 & 0.010 & 0.031 & nd & nd & nd \\
\hline Iron & 0.176 & 0.192 & 0.456 & nd & nd & nd \\
\hline Zinc & 0.044 & 0.025 & 0.016 & 0.054 & 0.010 & 0.030 \\
\hline Manganese & 0.045 & 0.030 & 0.024 & 0.017 & 0.019 & 0.016 \\
\hline Cadmium & 0.071 & 0.046 & 0.042 & 0.044 & 0.025 & 0.158 \\
\hline Lead & 0.029 & 0.013 & 0.012 & 0.025 & 0.030 & 0.024 \\
\hline Cobalt & 0.298 & 0.414 & 0.422 & 0.033 & 0.046 & 0.042 \\
\hline Nickel & 0.055 & 0.058 & 0.047 & 0.029 & 0.013 & 0.028 \\
\hline Carbonate & nd & nd & nd & 0.621 & 0.393 & 0.167 \\
\hline Chloride & nd & nd & nd & 0.483 & 0.612 & 0.316 \\
\hline Hydroxide & nd & nd & nd & 0.653 & 0.545 & 0.512 \\
\hline Nitrate & nd & nd & nd & 0.838 & 0.774 & 0.781 \\
\hline Phosphate & nd & nd & nd & 0.949 & 0.901 & 0.842 \\
\hline Sulphate & nd & nd & nd & 0.211 & 0.301 & 0.189 \\
\hline
\end{tabular}

nd $=$ not determined 


\subsubsection{Anions analysis on washing water samples}

C99 multi-parameter bench photometer (HANNA, USA) was used for the determination of $\mathrm{SO}_{4}{ }^{2-}, \mathrm{PO}_{3}{ }^{-}$and $\mathrm{NO}_{3}{ }^{-}$in biodiesel washing water. $10 \mathrm{~mL}$ of each kind of the biodiesel washing water was put into a vial bottle and the recommended standard reagent powder (HI93713-0 reagent powder for $\mathrm{PO}_{3}{ }^{-}$and HI93728-0 reagent powder for $\mathrm{NO}_{3}{ }^{-}$) was added and then shaken for $5 \mathrm{~min}$, resulting into a change in colour of the sample. Another bottle containing blank water sample was then inserted into the holder to obtain zero reading displayed. The sample was then inserted into the compartment and the required anion test method was selected, the concentration of the anion (in $\mathrm{mg} / \mathrm{L}$ ) was displayed by pressing the read button.

$\mathrm{CO}_{3}^{-}, \mathrm{Cl}^{-}$and $\mathrm{OH}^{-}$concentrations in washing water were determined through titration method.

In each case, $20 \mathrm{~mL}$ of washing water sample was titrated against the required chemical reagent, using the appropriate indicator. Expressions for the determination of the anions are shown below

$$
\begin{aligned}
& \text { Chloride ion }(\mathrm{mg} / \mathrm{L})= \\
& \qquad \frac{\text { Volume of } \mathrm{AgNO}_{3} \text { used } \times 0.1 \mathrm{M} \times 35.5 \times 1000}{20 \mathrm{~mL} \text { of the sample }}
\end{aligned}
$$

$$
\begin{aligned}
& \mathrm{CO}_{3}^{-} \text {or } \mathrm{OH}(\mathrm{mg} / \mathrm{L})= \\
& \frac{\text { Volume of } \mathrm{HCI} \text { used } \times 0.01 \mathrm{M} \times M W \text { of Anion } \times 1000}{20 \mathrm{~mL} \text { of the sample }}
\end{aligned}
$$

\subsection{Impact Analysis of the Potential Emission}

Using ReCiPe Midpoint (I) V1.12 / World Recipe I method (SimaPro 8 software), characterisation and normalisation of the potential emissions from biodiesel and washing water were carried out to determine the impacts of the emissions on human health and environment. Climate change, terrestrial acidification, freshwater eutrophication, human toxicity, terrestrial ecotoxicity and freshwater ecotoxicity were the categories considered in the characterization of the emissions.

\section{Results and Discussion}

\subsection{Analysis of Variation}

Analysis of variation was carried out in order to determine the effects of the production parameters (both on individual basis and combined form) on the yield of biodiesel (Fig. 1 and Fig. 2).

3.1.1. Main effects of production parameters on biodiesel yield Considering Fig. 1, the results showed that increase in reaction temperature up to $54^{\circ} \mathrm{C}$ favoured biodiesel yield; beyond this temperature, biodiesel yield decreased. At temperature above $54^{\circ} \mathrm{C}$, transesterification reaction (reversible reaction) experienced backward reaction which lowered biodiesel yield production [15, 24]. Increase in methanol/oil mole ratio from 5 to 7

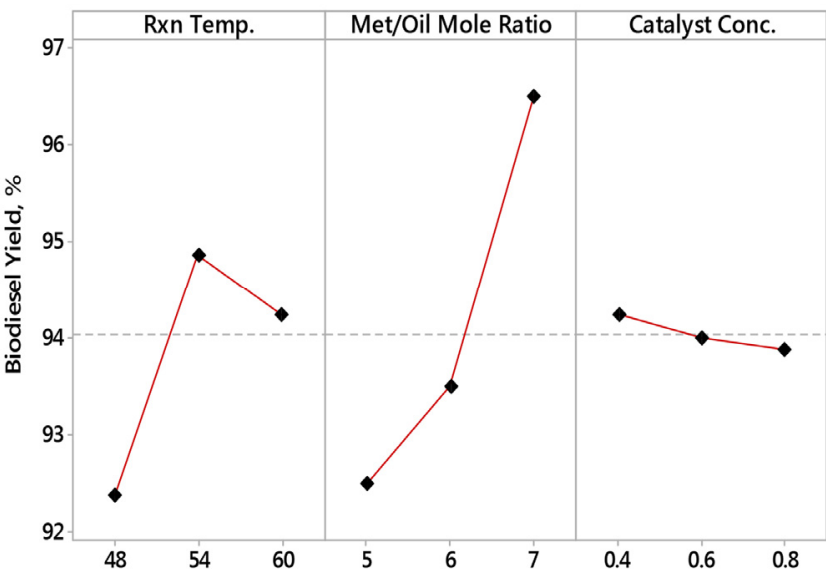

Fig. 1. The main effects of the three factors on biodiesel yield.

resulted into increase in biodiesel yield, this implies that increase in the mole ratio favours forward and complete reaction of biodiesel production.

Increase in catalyst concentration from 0.4 to $0.8 \mathrm{wt} / \mathrm{wt} \%$ resulted in decrease in biodiesel yield, though the effect of change in catalyst concentration on the yield was not significant. Increase in $\mathrm{KOH}$ catalyst resulted in the introduction of excess $\mathrm{KOH}$ which then reacted with methanol to form soap (esterification reaction), thereby lower biodiesel production [34-35]. From Fig. 1, it can be seen that the main effect of methanol/oil mole ratio on high yield of biodiesel is more significant compare to any of the other two main effects [13].

\subsubsection{Interaction effects of the production parameters on biodiesel yield}

Interaction effects of the three variables on the yield are represented in contour plots as shown in Fig. 2. The contour plot of biodiesel yield against catalyst concentration and methanol/oil mole ratio shows highest yield of biodiesel (98\%) at $0.5 \mathrm{wt} / \mathrm{wt} \%$ catalyst concentration and 7 methanol/oil mole ratio, while the lowest value of $92 \%$ biodiesel yield was obtained at catalyst concentration of $0.6 \mathrm{wt} / \mathrm{wt} \%$ and 5.5 methanol/oil mole ratio (Fig. 2(a)). Considering the interaction effects of methanol/oil mole ratio and reaction temperature on biodiesel yields (Fig. 2(b)), it can be observed that highest biodiesel yield of $96 \%$ was obtained at 7 methanol/oil mole ratio and reaction temperature of $54^{\circ} \mathrm{C}$. The least value of biodiesel yield (90\%) was observed at methanol/oil mole ratio of 5 and reaction temperature of $48^{\circ} \mathrm{C}$.

The interaction effect of catalyst concentration and reaction temperature on biodiesel yield shows that $95 \%$ yield of biodiesel was obtained at reaction temperature of $57^{\circ} \mathrm{C}$ and $0.4 \mathrm{wt} / \mathrm{wt} \%$ catalyst concentration (Fig. 2(c)).

In accordance with the main effect and the interaction effects of the three variables on biodiesel yield, optimization plot with optimum desirability of 1.00 shows that the optimum biodiesel yield of $99 \%$ can be obtained at optimal conditions of $54^{\circ} \mathrm{C}$ reaction temperature, 7 mole ratio of methanol to oil and $0.4 \mathrm{wt} / \mathrm{wt} \%$ catalyst concentration [13, 15, 24]. 

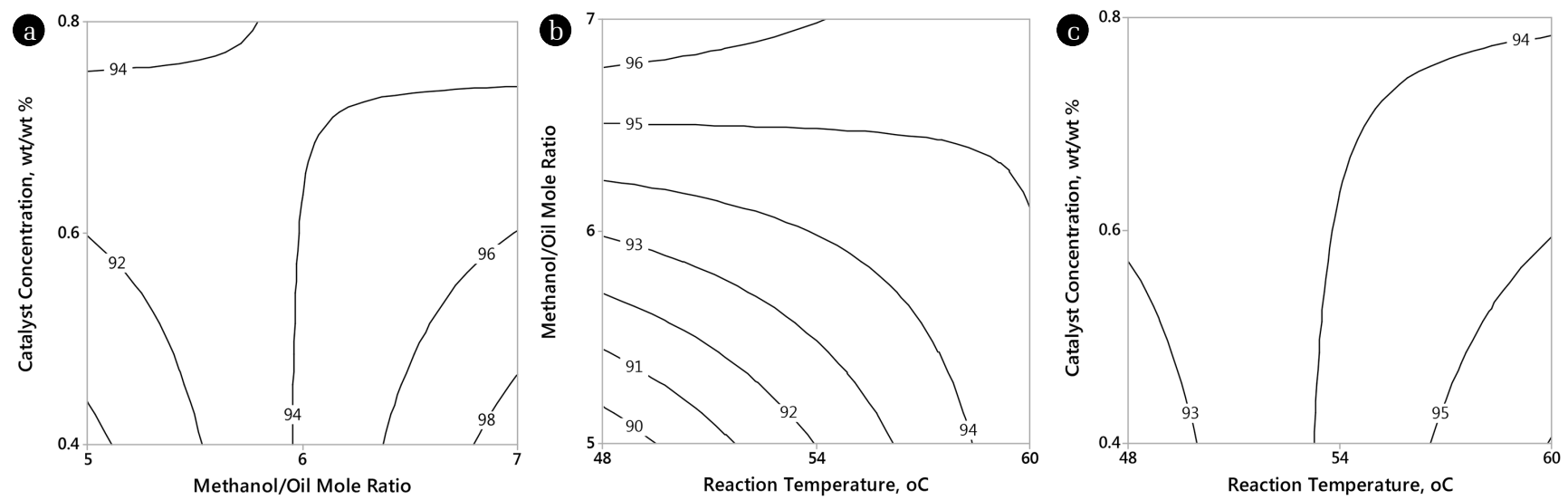

Fig. 2. Interactive effects of the three factors on biodiesel yield.
(a) shows the interactive effects of catalyst concentration and methanol/oil mole ratio on the yield
(b) shows the interactive effects of methanol/oil mole ratio and reaction temperature on the yield
(c) shows the interactive effects of catalyst concentration and reaction temperature on the yield

\subsection{Characterisation of the Potential Emissions from Biodiesel}

The results of the characterization of the six categories are shown in Fig. 3 and Table 4. In each category, the highest cumulative quantity of emissions from the three different storage conditions was assigned $100 \%$ [32-33]. For instance, climate change category has $6.21 \times 10^{-6} \mathrm{~kg} \mathrm{CO}_{2}(100 \%)$ emission from biodiesel in atmosphere, $3.9321 \times 10^{-6} \mathrm{~kg} \mathrm{CO}$ (63\%) emission from biodiesel in refrigerator and $1.67 \times 10^{-6} \mathrm{~kg} \mathrm{CO}_{2}(27 \%)$ emission from biodiesel in vacuum. It is important to mention that the categories cannot be compared under characterization because different parameters were used in the analysis of these categories; hence the units of the categories differ.

It was observed that emissions from biodiesel in atmosphere were highest in climate change, freshwater eutrophication, human toxicity and freshwater ecotoxicity. Emissions from biodiesel in refrigerator were highest in terrestrial acidification and freshwater

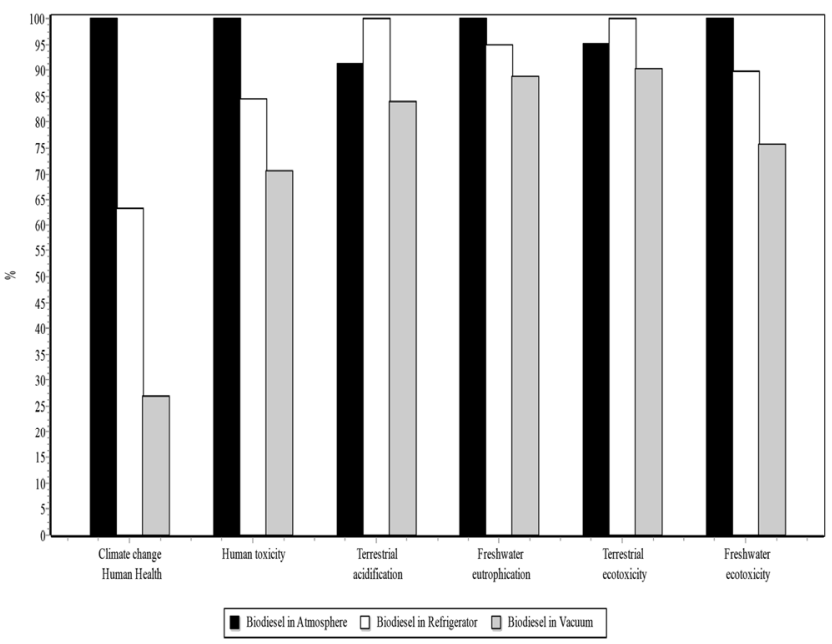

Fig. 3. Characterisation of potential emissions from biodiesel and washing water. ecotoxicity. In each category, potential emissions from biodiesel in vacuum were the least.

It can be inferred that the exposure of biodiesel and washing water to water vapour, gaseous substances and particulate matter in the atmosphere contributed greatly to high level of impurities/emissions obtained. Biodiesel, an oxygenated fuel with poor oxidation stability, can easily react with oxygen or any compound in the atmosphere to generate unwanted pollutants [32]. For instance, biodiesel and washing water in atmosphere had the highest quantity of Phosphate $\left(3.13 \times 10^{-4}, 100 \%\right)$ and this resulted in $100 \%$ freshwater eutrophication. Also, human toxicity (determined by relating emissions in this category to $1 \mathrm{~kg}$ of Dichloro Benzene equivalent) was highest under this storage condition.

Biodiesel and washing water in refrigerator had the highest level of emissions in terrestrial acidification and terrestrial ecotoxicity simply because of their great level of exposure to volatile organic compounds that reacted or contaminated the samples. That is, terrestrial ecotoxicity (expressed in $1 \mathrm{~kg}$ of Dichloro Benzene equivalent) had $9.18 \times 10^{-4} \mathrm{~kg}(100 \%)$ of emissions from biodiesel and washing water in refrigerator; $8.784 \times 10^{-4} \mathrm{~kg}(95 \%)$ of emissions from biodiesel and washing water in atmosphere; and $8.284 \times 10^{-4} \mathrm{~kg}(89 \%)$ of emissions from biodiesel and washing water in vacuum. This result indicated that the exposure of volatile organic compounds (such as CFC) was higher in the refrigerator compared to any of the other two storage environment [7, 32].

The presence of heavy metals (such as Arsenic, Beryllium, Cadmium, Cobalt, Lead, Nickel, etc.) in biodiesel and washing water exposed to atmosphere was more than those obtained from the samples of biodiesel and washing water in refrigerator or vacuum. And this accounted for the reason the emissions of samples from atmosphere had $100 \%$ in human toxicity and freshwater ecotoxicity [32].

\subsection{Normalisation of the Potential Emissions from Biodiesel}

Fig. 4 shows the results obtained from the normalization of the six categories. Norminalisation of the categories were considered 
Table 4. Characterisation of Potential Emissions from Biodiesel and Washing Water

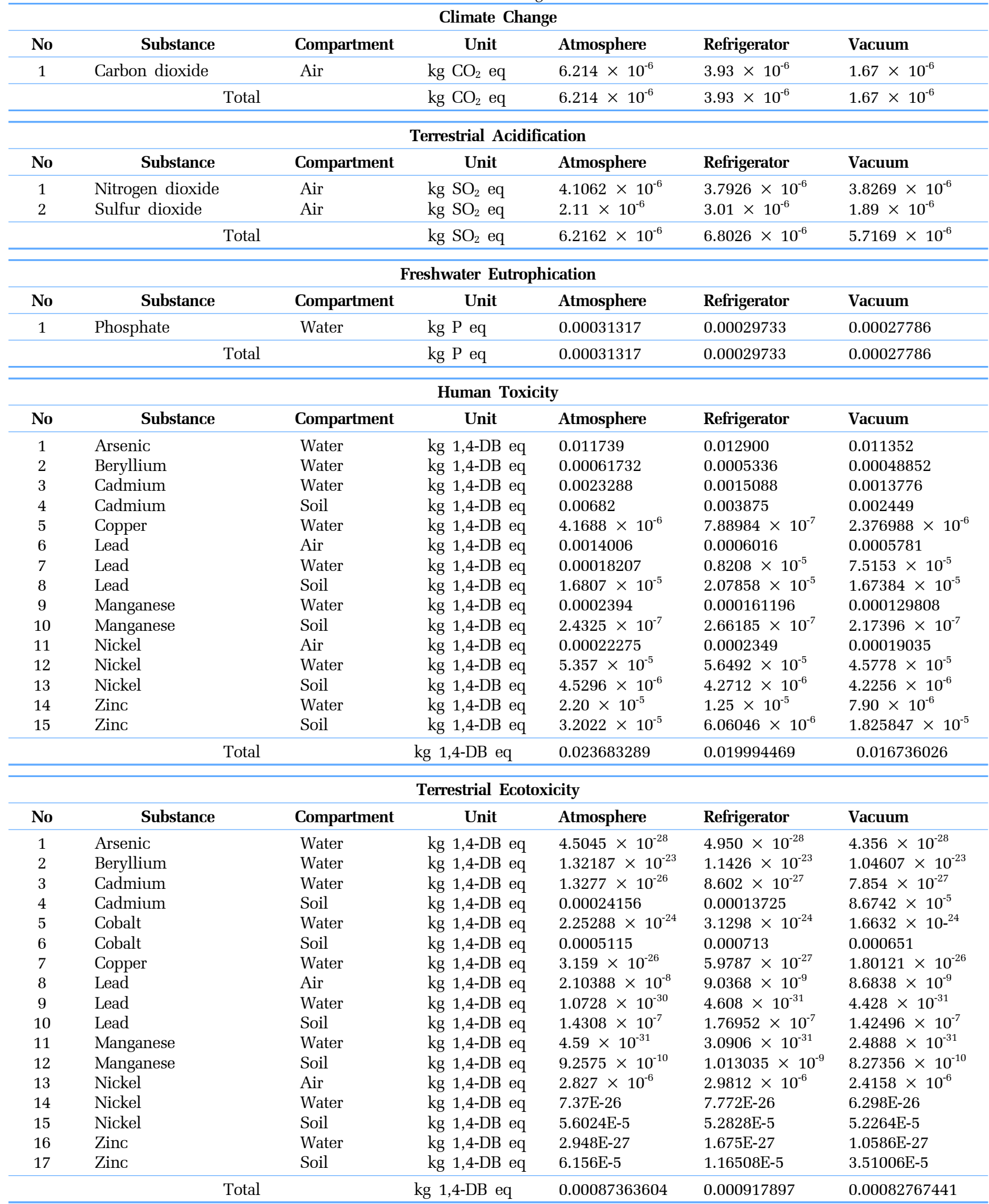




\begin{tabular}{|c|c|c|c|c|c|c|}
\hline \multicolumn{7}{|c|}{ Freshwater Ecotoxicity } \\
\hline No & Substance & Compartment & Unit & Atmosphere & Refrigerator & Vacuum \\
\hline 1 & Arsenic & Water & $\mathrm{kg}$ 1,4-DB eq & 0.00014196 & 0.000156 & 0.00013728 \\
\hline 2 & Beryllium & Water & kg 1,4-DB eq & 0.0291885 & 0.02523 & 0.0230985 \\
\hline 3 & Cadmium & Water & kg 1,4-DB eq & 0.00064255 & 0.0004163 & 0.0003801 \\
\hline 4 & Cadmium & Soil & $\mathrm{kg} 1,4-\mathrm{DB}$ eq & $6.556 \times 10^{-6}$ & $3.725 \times 10^{-6}$ & $2.3542 \times 10^{-6}$ \\
\hline 5 & Cobalt & Water & $\mathrm{kg} 1,4-\mathrm{DB}$ eq & 0.009834 & 0.013662 & 0.00726 \\
\hline 6 & Cobalt & Soil & kg 1,4-DB eq & 0.00021153 & 0.00029486 & 0.00026922 \\
\hline 7 & Copper & Water & kg $1,4-\mathrm{DB}$ eq & 0.006372 & 0.00120596 & 0.00363322 \\
\hline 8 & Lead & Air & kg 1,4-DB eq & $1.43636 \times 10^{-9}$ & $6.1696 \times 10^{-10}$ & $5.9286 \times 10^{-10}$ \\
\hline 9 & Lead & Water & kg 1,4-DB eq & $1.23372 \times 10^{-5}$ & $5.2992 \times 10^{-6}$ & $5.0922 \times 10^{-6}$ \\
\hline 10 & Lead & Soil & kg $1,4-\mathrm{DB}$ eq & $2.5725 \times 10^{-8}$ & $3.1815 \times 10^{-8}$ & $2.562 \times 10^{-8}$ \\
\hline 11 & Manganese & Water & kg 1,4-DB eq & 0.00019845 & 0.000133623 & 0.000107604 \\
\hline 12 & Manganese & Soil & kg 1,4-DB eq & $1.9425 \times 10^{-7}$ & $2.12565 \times 10^{-7}$ & $1.73604 \times 10^{-7}$ \\
\hline 13 & Nickel & Air & kg 1,4-DB eq & $1.606 \times 10^{-6}$ & $1.6936 \times 10^{-6}$ & $1.3724 \times 10^{-6}$ \\
\hline 14 & Nickel & Water & kg 1,4-DB eq & 0.005412 & 0.0057072 & 0.0046248 \\
\hline 15 & Nickel & Soil & kg 1,4-DB eq & $2.22308 \times 10^{-5}$ & $2.09626 \times 10^{-5}$ & $2.07388 \times 10^{-5}$ \\
\hline 16 & Zinc & Water & kg 1,4-DB eq & 0.00033088 & 0.000188 & 0.000118816 \\
\hline \multirow[t]{2}{*}{17} & Zinc & Soil & kg $1,4-\mathrm{DB}$ eq & $2.6676 \times 10^{-6}$ & $5.04868 \times 10^{-7}$ & $1.521026 \times 10^{-6}$ \\
\hline & & & $\mathrm{kg}$ 1,4-DB eq & 0.052377489 & 0.047026373 & 0.039660818 \\
\hline
\end{tabular}

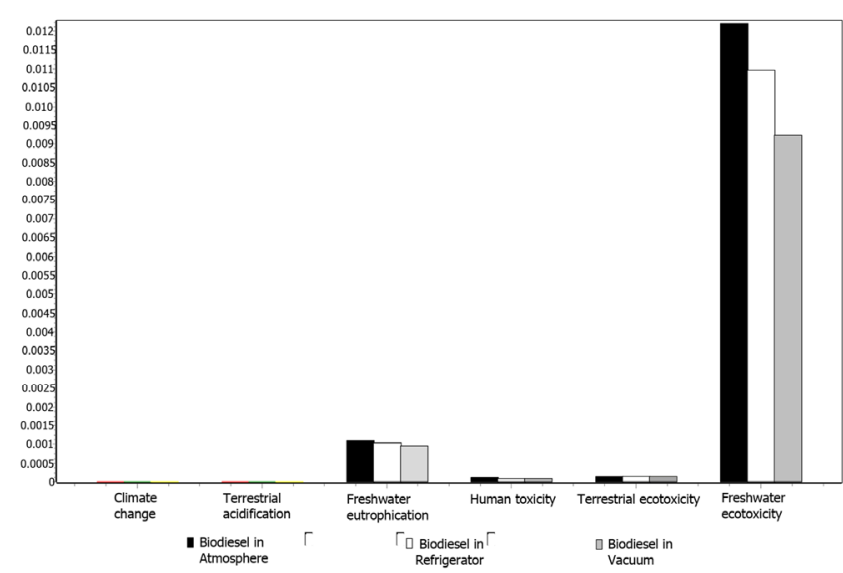

Fig. 4. Normalisation of potential emissions from biodiesel and washing water.

so as to compare or relate the extent of the impacts of the categories to $1 \mathrm{~kg}$ of biodiesel produced; that is $\mathrm{kg}$ emissions in each category per kg biodiesel produced. Comparatively, freshwater ecotoxicity category had the most pronounced negative impact of the emissions from the samples. The second negative impact was freshwater eutrophication, while the negative impacts (categories) of the other categories were insignificant. That is, the emissions affect freshwater organisms most by causing exponential growth of microorganisms and the destruction of aquatic animals [26, 36].

The values obtained in terrestrial and human toxicity showed that the impacts of the potential emissions on plants and human are mild. While the results of climate change and terrestrial acidification revealed insignificant impacts of emissions from biodiesel and washing water [2, 7].

In general, emissions from samples exposed to atmosphere had the most pronounced negative effects on plants, animals and man; as reported by researchers [2, 26, 36]. Emissions from samples stored in the refrigerator came second in term of negative environ- mental impacts, while emissions from samples stored in the vacuum had the least negative impacts. In addition, this trend of the results could be attributed to the fact that atmosphere serves as a better medium for the promotions of various reactions (such as oxidation, thermal and hydrolysis reactions) compare to refrigerated condition, while no significant reaction takes place in the vacuum except few ones within the samples.

\section{Conclusions}

Based on the potential emissions obtained, the present study shows that the order of preference of the storage environments of biodiesel is vacuum environment, refrigerated condition and exposure to the atmosphere. Exposure to atmosphere promotes certain reactions of biodiesel (an oxygenated and unsaturated compound) while vacuum environment hardly encourage any form of reaction or contamination.

\section{Acknowledgments}

The authors would like to thank Covenant University Centre for Research Innovation and Discovery (CUCRID) Ota, Nigeria for the provision financial support that made the publication of this research work possible.

\section{References}

1. Ayoola AA, Hymore KF, Omonhinmin CA. Optimization of biodiesel production from selected waste oils using response surface methodology. Biotechnology 2017;16:1-9.

2. William HK. Biodiesel basics and beyond: A comprehensive guide to production and use for the home and farm. Ontario 
Canada: Aztext Press; 2006.

3. Lee S, Shah YT. Biofuels and bioenergy: Processes and technologies. 6000 broken sound parkway NW, suite 300 boca raton, FL: CRC press, Taylor and Francis group; 2013.

4. Debalina S, Ralph WP. Chemicals from biomass: Integrating bioprocessors into chemical production complexes for sustainable development. 6000 broken sound parkway NW, suite 300 boca raton, FL: CRC press, Taylor and Francis group; 2013.

5. Evangelos GG. A statistical investigation of biodiesel physical and chemical properties and their correlation with the degree of unsaturation. Renew. Energy 2013;50:858-878.

6. Harold HS. Chemistry of fossil fuels and biofuels. New York: Cambridge University press; 2013.

7. Yang HH, Chien SM, Lo MY, Lan JC, Lu WC, Ku YY. Effects of biodiesel on emissions of regulated air pollutants and polycyclic aromatic hydrocarbons under engine durability testing. Atmos. Environ. 2007;41:7232-7240.

8. Kumar M, Ramesh A, Nagalingam B. An experimental comparison of methods and jatropha oil in a compression ignition engine. Biomass Bioenerg. 2003;25:309-318.

9. Tan KT, Lee KT, Mohammed AR. Potential of waste palm cooking oil for catalyst-free biodiesel production. Energy 2011;36:2085-2088.

10. Parag S, Sayali J, Milind J. A review on prediction of properties of biodiesel and blends of biodiesel. Procedia Eng. 2013;51:395-402.

11. Yan F, Yuan Z, Lü P, Luo W, Yang L, Deng L. Synthesis of biodiesel by $\mathrm{Fe}(\mathrm{II})-\mathrm{Zn}$ double-metal cyanide complexes. J. Fuel Chem. Technol. 2010;38:281-286.

12. Ali EN, Tay CI. Characterization of biodiesel produced from palm oil via base catalyzed transesterification. Procedia Eng. 2013;53:7-12.

13. Ayoola AA. Production and life cycle assessment of biodiesel from three waste oils [thesis]. Ota, Ogun State: Covenant Univ.; 2015.

14. Leung DY, Wu X, Leung MK. A review on biodiesel production using catalysed trans-esterification. Appl. Energ. 2010;87: 1083-1095.

15. Zahira Y, Masita M, Mohammad A, Zahangir A. Overview of the production of biodiesel from waste cooking oil. Renew. Sust. Energ. Rev. 2013;18:184-193.

16. Zhang Y, Dube MA, Mclean DD, Kates M. Biodiesel production from waste cooking oil: Economic assessment and sensitivity analysis. Bioresour. Technol. 2003;90:229-240.

17. Ayoola AA, Adeeyo OA, Ojewumi ME, Ibiye BP. Oxidation stability of fatty acid methyl ester under three different conditions. J. Energy Technol. Policy 2016;6:6-11.

18. Issariyakul T. Development of biodiesel production processes from various vegetable oils [thesis]. Saskatchwan: Univ. of Saskatchewan; 2011.

19. Jacobson K, Gopinath R, Meher LC, Dalai AK. Solid acid catalyzed biodiesel production from waste cooking oil. Appl. Catal.
B-Environ. 2008;85:86-91.

20. Kulkarni MG, Gopinath R, Meher LC, Dalai AK. Solid acid catalyzed biodiesel production by simultaneous esterification and transesterification. Green Chem. 2006;8:1056-1062.

21. Sharma YC, Singh B. Development of biodiesel: Current scenario. Renew. Sust. Energ. Rev. 2009;13:1646-1651.

22. Lou WY, Zong MH, Duan ZQ. Efficient production of biodiesel from high free fatty acid containing waste oils using various carbohydrate-derived solid acid catalysts. Bioresour. Technol. 2008;99:8752-8758.

23. Meher LC, Sagar DV, Naik SN. Technical aspects of biodiesel production by transesterification - A review. Renew. Sust. Energ. Rev. 2006;10:248-268.

24. Mekhilef S, Siga S, Saidur R. A review on palm oil biodiesel as a source of renewable fuel. Renew. Sust. Energ. Rev. 2011;15:1937-1949.

25. Pugazhvadivu M, Jeyachandran K. Investigations on the performance and exhaust emissions of a diesel engine using preheated waste frying oil as fuel. Renew. Energ. 2005;30:2189-2202.

26. Sabine M, Wendy G. Human health effects of heavy metals. Environmental Science and Technology Briefs for Citizens. Kansas State University: 2009. p. 1-6.

27. Silalertruksa T, Gheewala SH. Environmental sustainability assessment of palm biodiesel production from Thailand. Energy 2012;43:306-314.

28. Muradov NZ, Veziroglu TN. Carbon-neutral fuels and energy carriers. 6000 broken sound parkway NW, Suite 300 boca raton, FL: CRC press, Taylor and Francis group; 2013.

29. Bernesson SD, Hansson P. A limited LCA comparing large scale and small scale production of ethanol for heavy engines under Swedish conditions. Biomass Bioenerg. 2006;30:46-57.

30. European Commission. Environment [Internet]. European Commission; c2017 [cited 30 March 2017]. Available from: http://www.ec.europa.eu/environment.

31. United Nations. Transforming World: The 2030 Agenda for sustainable development. United Nations Sustainable Development Summit; 21-25 September 2015; UN Headquarters, New York, USA. p. 1-41.

32. Marta GV, Pinto G, Martins F. Life cycle analysis of biodiesel production fuel. Procedia Technol. 2011;92:1087-1094.

33. Olivier J, Manuele M, Raphaël C, et al. IMPACT 2002+: A new life cycle impact assessment methodology. Int. J. Life Cycle Ass. 2003;8:324-330.

34. Chen Y, Xiao B, Chang J, Fu Y, Lv P, Wang X. Synthesis of biodiesel from waste cooking oil using immobilized lipase in fixed bed reactor. Energ. Convers. Manage. 2009;50:668-673.

35. Rashid U, Anwar F. Production of biodiesel through optimized alkaline-catalyzed transesterification of rapeseed oil. Fuel 2008;87:265-273.

36. Swanson KJ, Madden MC, Ghio AJ. Biodiesel exhaust: The need for health effects research. Environ. Health Persp. 2007;115:496-499. 